\title{
Highly porous S-doped carbons
}

\author{
Marta Sevilla and Antonio B. Fuertes ${ }^{*}$ \\ Instituto Nacional del Carbón (CSIC), P.O. Box 73, 33080 Oviedo, Spain
}

\begin{abstract}
Porous sulphur-doped carbons have been prepared by using polythiophene (PTh) as carbon precursor and $\mathrm{KOH}$ as activating agent. The activation process was carried out under several operating conditions, i. e. a KOH/PTh weight ratio of 2 or 4 , and reaction temperatures in the $600-850{ }^{\circ} \mathrm{C}$ range. The porous carbons thus obtained exhibit very large apparent surface areas and high pore volumes of up to $3000 \mathrm{~m}^{2} \cdot \mathrm{g}^{-1}$ and $1.75 \mathrm{~cm}^{3} \cdot \mathrm{g}^{-1}$ respectively for a sample prepared at $850{ }^{\circ} \mathrm{C}$ and with a $\mathrm{KOH} / \mathrm{PTh}$ weight ratio $=2$. The pore size distribution of these carbons gradually changes with the reaction temperature. Thus, whereas the porosity of the samples prepared at $600{ }^{\circ} \mathrm{C}$ is mostly formed by micropores $\sim 1 \mathrm{~nm}$, those obtained at $850{ }^{\circ} \mathrm{C}$ exhibit two pore systems with diameters of $\sim 1 \mathrm{~nm}$ and $\sim 2.5 \mathrm{~nm}$. These polythiophene-based porous carbons have large sulphur contents in the 3-12 wt \% range, and this percentage decreases as the reaction temperature rises. The sulphur present in these carbons forms two types of functional groups (i. e. sulphide -C-S-C- and sulphone -C-SO ${ }_{2}-\mathrm{C}-$ ) which act as bridges between adjacent aromatic rings.
\end{abstract}

Keywords: activated carbon; polythiophene; sulphur; micropores

\footnotetext{
* Corresponding author. Tel: 34985 119090. E-mail address: abefu@incar.csic.es (A. B. Fuertes)
} 


\section{Introduction}

The fabrication of porous carbons with appropriate structural and chemical properties has recently generated a great deal of interest because of their applicability in numerous emergent applications such as: i) the storage of electrical energy in supercapacitors [1], ii) the immobilization and separation of large biomolecules [2], iii) $\mathrm{CO}_{2}$ capture [3], iii) hydrogen storage [4], iv) the high-capacity adsorption of specific contaminants in liquid phase (e. g. dyes, heavy metal ions, anions, etc) [5], v) their role as catalytic supports in fuel cells [6], etc. To optimize the use of porous carbons in each of these cases, it is important that the properties of the material match the requirements of the application. To this end, two synthesis strategies have been adopted: a) the design of an appropriate pore architecture and b) the incorporation of specific functional groups onto the carbon surface. The two strategies are complementary and can be applied to the same material. Examples of the first strategy include the fabrication of carbons with a well-structured porosity in the micropore and/or mesopore range. Thus, mesoporous carbons with uniform and size-tunable pores, useful for the adsorption of bulky molecules (e. g. dyes, proteins, etc), are commonly fabricated by means of nanocasting techniques using mesoporous silica as hard template [7]. In addition, microporous carbons with pores of around $1 \mathrm{~nm}$, which have proved to be very effective for $\mathrm{CO}_{2}$ capture [8], $\mathrm{H}_{2}$ storage [9] or as electrodes in supercapacitors [10], can be produced by chemical activation of different precursors with $\mathrm{KOH}$ (e. g. biomass, coal or petroleum pitch, polymers, etc).

The second strategy based on the functionalization of the carbon surface improves the level of utility of the porous carbons due to: a) the fine-tuning of the interactions between the chemical groups attached to the carbon surface and the guest species (e. g. adsorbable molecules and ions, nanoparticles with catalytic or electrochemical properties, etc) or b) the incorporation of functional groups with catalytic properties (e. 
g. sulphonic groups) [11]. There are numerous ways in which functional groups can be incorporated onto the carbon surface. Most of them are based on the reaction of carbon with different chemical agents (grafting reactions), which results in the covalent attachment of a variety of functional groups. An alternative and easier route to produce functionalized carbons is to use organic substances containing heteroatoms such as nitrogen or sulphur (e. g. acrylonitrile, pyrrole, aniline, thiophene, etc) as carbon precursors. This option, which is sometimes used in combination with nanocasting techniques, gives rise to carbon materials with $\mathrm{N}$ - or S-based functional groups. The synthesis procedure for the production of such carbons involves infiltrating the carbon precursor inside the pores of a hard template (e. g. SBA-15) and then the composite is subjected to polymerization, carbonization and finally the template is removed. This methodology has been widely employed to produce N-doped templated carbons which exhibit a good electrical conductivity, high capacitance values and an enhanced capacity to adsorb anions [12].

The incorporation of sulphur functional groups to the carbon framework gives rise to materials with outstanding specific properties. In fact, it has been reported that S-doped carbons exhibit an excellent capacity to adsorb heavy-metals [13], an enhanced specific capacitance [14] or a superior performance as catalytic supports of Pt nanoparticles [15]. A facile route to synthesize carbons with these properties is to use sulphur-rich compounds as carbon precursors. However, unlike the synthesis of N-doped carbons, only a few authors have focused on the fabrication of S-doped porous carbons $[13,16$, 17]. Thus, Shin et al. reported the synthesis of templated mesoporous carbons containing 4-7 wt \% sulphur by using thiophenemethanol as precursor and SBA-15 as template [13]. This carbon exhibits an excellent mercury sorption performance due to the high $\mathrm{S} \rightarrow \mathrm{Hg}$ affinity. 
In spite of the practical interest of sulphur-enriched porous carbons, there is no work devoted to their fabrication by means of conventional activation procedures (i. e. physical or chemical activation). Accordingly, we present here for the first time a simple conventional synthesis strategy to highly porous S-doped carbons. Thus, our main purpose is to prepare activated carbons that combine a well-developed porosity (i. e. large apparent surface areas and high pore volumes) with high sulphur contents by means of a chemical activation route. In a recent work, we reported a novel route to obtain N-doped porous carbons, which consists of the chemical activation of polypyrrole, a nitrogen-rich polymeric material, with $\mathrm{KOH}[18,19]$. In the present work, we apply a similar synthetic strategy to fabricate highly porous S-doped carbons using as precursor a sulphur-rich polymer (i. e. polythiophene), synthesized by the chemical polymerization of thiophenemethanol. The polythiophene (PTh) is subjected to one-step standard chemical activation with $\mathrm{KOH}$. The textural and chemical characteristics of the S-doped porous carbons are controlled by modifying the amount of activating agent $(\mathrm{KOH} / \mathrm{PTh}$ ratio) and the reaction temperature. In this way, a variety of sulphur-rich carbons with a high porosity are obtained. The chemical and structural characteristics of the S-doped porous carbons are investigated by means of different experimental techniques. Special attention is paid to establishing the nature of the sulphur functionalities present in these materials.

\section{Experimental}

\subsection{Synthesis of porous carbons}

Polythiophene (PTh) was prepared using $\mathrm{FeCl}_{3}$ as oxidant. In a typical synthesis, $3 \mathrm{~g}$ of 2-thiophenemethanol (Aldrich) in $20 \mathrm{~mL}$ of $\mathrm{CH}_{3} \mathrm{CN}$ (Aldrich) was slowly added, under vigorous stirring, to a solution of $\mathrm{FeCl}_{3}$ (28.9 g, Aldrich) in $100 \mathrm{~mL} \mathrm{CH} \mathrm{CH}_{3} \mathrm{CN}$. Afterwards, the mixture was kept under stirring, at room temperature, for $15 \mathrm{~h}$. The 
polymer (PTh) thus obtained was separated by filtration, washed with abundant distilled water and then with acetone. Finally, it was dried $\left(120^{\circ} \mathrm{C}\right.$ for several hours $)$ and stored. The PTh yield was around $95 \%$.

The PTh was chemically activated by heating a PTh-KOH mixture $(\mathrm{KOH} / \mathrm{PTh}$ at a weight ratio of 2 or 4 ) under $\mathrm{N}_{2}$ up to a temperature in the $600-850{ }^{\circ} \mathrm{C}$ range (heating rate: $3{ }^{\circ} \mathrm{C} \cdot \mathrm{min}^{-1}$, holding time: $1 \mathrm{~h}$ ). To remove any residual inorganic salts, the activated samples were thoroughly washed several times with $\mathrm{HCl}(10 \mathrm{wt} \%)$ and then with distilled water until neutral pH. Finally, the carbon sample was dried in an oven at 120 ${ }^{\circ} \mathrm{C}$. The activated carbons thus synthesized were denoted as CT- $x-y$, where $x$ is the $\mathrm{KOH} / \mathrm{PTh}$ weight ratio and $y$ the reaction temperature $\left(\right.$ in $\left.{ }^{\circ} \mathrm{C}\right)$.

\subsection{Characterization}

Nitrogen sorption isotherms and the textural properties of the carbons were determined by nitrogen physisorption at $-196{ }^{\circ} \mathrm{C}$ in a conventional volumetric apparatus (Micromeritics ASAP 2020). The apparent surface area was calculated by the BET method from adsorption data in the partial pressure $\left(\mathrm{p} / \mathrm{p}_{\mathrm{o}}\right)$ range of 0.04 to 0.2 and the total pore volume was determined from the amount of nitrogen adsorbed at a relative pressure of 0.99 . The micropore volume was obtained via a t-plot analysis. The pore size distributions (PSDs) were determined by means of the Non Local Density Functional Theory (NLDFT) method using nitrogen adsorption data and assuming a slit pore model. Scanning electron microscopy (SEM) images were obtained using a Quanta FEG650 (FEI) instrument. Transmission electron micrographs (TEM) were taken on a JEOL (JEM-2000 EX II) microscope operating at $160 \mathrm{kV}$. Diffuse reflectance infrared (IR) spectra of the powders of the materials were recorded on a Nicolet Magna-IR 560 spectrometer fitted with a diffuse reflection attachment. X-ray photoelectron spectroscopy (XPS) was carried out by means of a Specs spectrometer, using $\mathrm{Mg} \mathrm{K \alpha}$ 
$(1253.6 \mathrm{eV})$ radiation from a double anode at $50 \mathrm{w}$. Binding energies for the highresolution spectra were calibrated by setting $\mathrm{C} 1$ s to $284.6 \mathrm{eV}$. A LECO Tru Spec microanalyzer was used to calculate the $(\mathrm{C}, \mathrm{H}, \mathrm{O})$ composition of the materials. The sulphur content of the samples was determined by means of a LECO S-632 analyzer. Pyrolysis of polythiophene was investigated by means of thermogravimetric analysis (TGA) which was performed on a C. I. Electronics apparatus. In a typical experiment the polymer samples was heated under inert atmosphere up to $800^{\circ} \mathrm{C}$ (heating rate: 5 $\left.{ }^{\circ} \mathrm{C} \cdot \mathrm{min}^{-1}\right)$. Once, the pyrolysis is completed, the carbonaceous residue is burned out in air.

\section{Results and discussion}

\subsection{Structural characteristics of porous carbons}

The SEM image displayed in Figure 1a shows that the polythiophene (PTh) is made up of microspheres with diameters in the $0.3-1.3 \mu \mathrm{m}$ range. It can be seen that a large fraction of these microparticles are joined together. The carbonaceous product (C-PTh) obtained from the pyrolysis of the polythiophene retains its original spherical morphology demonstrating that the polymer does not fuse during the carbonization step. At this point, it is worth noting that the carbonized PTh (C-PTh sample) already exhibits a certain degree of porosity - a pore volume of $0.43 \mathrm{~cm}^{3} \cdot \mathrm{g}^{-1}$ and a BET surface area of $550 \mathrm{~m}^{2} \cdot \mathrm{g}^{-1}$ - which is essentially associated to the micropores, as can be inferred from the results in Table 1 and from the PSD shown in Figure S1 (Supporting Information). Further investigation of the thermal decomposition of polythiophene was carried out by means of TGA. The results obtained reveal that the pyrolysis of the polythiophene gives rise to a large amount of carbonaceous matter, i. e. $~ 56 \%$ (Figure S2 in Supporting Information). In addition, the TGA analysis shows that the iron compounds derived 
from $\mathrm{FeCl}_{3}$ have been totally removed as can be inferred from the fact that no inorganic residue remains after the combustion of the carbonaceous matter.

From Figure 1a, it can be deduced that the morphology of the polythiophene offers a large interfacial area for the reaction with $\mathrm{KOH}$. This guarantees that the activation process will occur uniformly, which is essential for a good pore development. The porous carbons resulting from the chemical activation process exhibit a sponge-like structure consisting of highly vesiculated particles of a relatively large size $(>40 \mu \mathrm{m})$ and with an irregular shape (see Figures $1 \mathrm{~b}$ and $1 \mathrm{c}$ ). The morphology of the activated carbon particles is completely different to that of polythiophene (see Fig. 1a), which suggests that melting of the reaction mixture $(\mathrm{PTh}-\mathrm{KOH})$ takes place during the chemical activation process. The porosity of these carbons is made up of randomly distributed uniform micropores, as illustrated by the TEM image in Figure 1d.

The nitrogen sorption isotherms and the corresponding pore size distributions (PSDs) of the activated carbons are displayed in Figure 2 for $\mathrm{KOH} / \mathrm{PTh}=2$ (Figs. 2a and 2b) and $\mathrm{KOH} / \mathrm{PTh}=4$ (Figs. $2 \mathrm{c}$ and $2 \mathrm{~d}$ ). Changes in the shape of the isotherms, as the activation temperature rises from $600{ }^{\circ} \mathrm{C}$ to $850{ }^{\circ} \mathrm{C}$, indicate modifications in the porous structure of the activated carbons, in particular a widening of the pores. Indeed, the PSDs shown in Figure $2 b$ and $2 d$ indicate that the porosity of the samples obtained at $600{ }^{\circ} \mathrm{C}$ (CT-2-600 and CT-4-600) is composed mostly of narrow micropores $(\sim 1 \mathrm{~nm})$. As the activation temperature increases, there is a gradual enlargement of the pore size up to $850^{\circ} \mathrm{C}$, at which point the activated carbons (CT-2-850 and CT-4-850) clearly exhibit two pore systems: one of them formed by uniform super-micropores $(\sim 1.2 \mathrm{~nm})$ and the other by pores in the micro-mesopore range. A comparison of Figure $2 \mathrm{~b}$ and Figure $2 \mathrm{~d}$ reveals that varying the amount of activating agent hardly has any effect on the pore size distributions. The textural parameters of these carbons are listed in Table 
1. For the two experimental series $(\mathrm{KOH} / \mathrm{PTh}=2$ and 4$)$, the surface area and the pore volume increase significantly with the activation temperature. It is worth noting the high BET surface area $\left(3000 \mathrm{~m}^{2} \cdot \mathrm{g}^{-1}\right)$ and pore volume $\left(1.75 \mathrm{~cm}^{3} \cdot \mathrm{g}^{-1}\right)$ achieved for the sample activated at $850^{\circ} \mathrm{C}$ and with $\mathrm{KOH} / \mathrm{PTh}=2(\mathrm{CT}-2-850)$. On the other hand, contrary to what might be expected, the samples prepared with $\mathrm{KOH} / \mathrm{PTh}=2$ exhibit, in relation to those obtained with $\mathrm{KOH} / \mathrm{PTh}=4$, a higher pore development, as can be inferred from the larger values for surface area $\left(\mathrm{S}_{\mathrm{BET}}\right.$ and $\left.\mathrm{S}_{\text {micro }}\right)$ and pore volume $\left(\mathrm{V}_{\mathrm{p}}\right.$ and $\left.\mathrm{V}_{\text {micro }}\right)$. Also important is the fact that the porosity of the activated samples is predominantly made up of micropores $(<2 \mathrm{~nm})$. However, it should also be noted that the percentage of microporosity clearly decreases as the reaction temperature increases (see Table 1 and Figs. $2 b$ and $2 d)$.

The activated carbon yields obtained after the chemical activation of polythiophene are listed in Table 1. It can be seen that the amount of activated carbon produced depends mainly on the reaction temperature, a notable decrease taking place from $\sim 40$ $\%$ to $\sim 20 \%$ as the temperature varies from $600{ }^{\circ} \mathrm{C}$ to $850{ }^{\circ} \mathrm{C}$.

\subsection{Chemical properties of S-doped carbons}

The chemical composition of the polymer and carbon samples is presented in Table 1. It can be seen that the sulphur content of the synthesized polythiophene $(28.2$ wt $\%)$ is significantly lower than that of the unsubstituted polythiophene (38.1 wt \%). This is due to the presence of a certain amount of oxygen $(\sim 11 \mathrm{wt} \%)$, which is forming oxygen functional groups (e.g. ether and carbonyl), as deduced from the IR and XPS spectra (vide infra). The activated carbons contain significant amounts of oxygen and sulphur, in the ranges $6-20 \mathrm{wt} \%$ and $3-12$ wt $\%$ respectively. These percentages vary with the activating conditions (e. g. temperature and $\mathrm{KOH} / \mathrm{PTh}$ ratio). Thus, there is a 
decrease in sulphur content as the activation temperature increases, which shows that as the activation progresses with temperature, the sulphur diminishes in relation to the carbon because it is preferentially removed. A decrease of the $(\mathrm{S} / \mathrm{O})$ atomic ratio with the activation temperature is also observed, which is a consequence of the superior thermal stability of oxygen functional groups (i. e. carbonyl, ether) in relation to the sulphur functionalities. This reduction in sulphur content is especially marked from 600 ${ }^{\circ} \mathrm{C}$ to $700{ }^{\circ} \mathrm{C}$. Remarkably, sample CT-4-600 contains a very large amount of sulphur (11.8 wt \%), which is one of the largest sulphur contents ever reported for a porous carbon. Finally, it should be pointed out that the oxygen present in the activated carbons is forming a variety of functional groups (vide infra), which are generated as a consequence of the oxidation reactions taking place during the chemical activation process [20].

The nature of the oxygen and sulphur functionalities was investigated by means of infrared and XPS spectroscopic techniques. The IR spectra of the polythiophene, carbonized polythiophene and porous carbons prepared at temperatures between $600{ }^{\circ} \mathrm{C}$ and $850{ }^{\circ} \mathrm{C}$ with $\mathrm{KOH} / \mathrm{PTh}=2$ are shown in Figure 3. Polythiophene exhibits welldefined peaks that are characteristic of this polymer (see Table S1) [21-26]. In contrast, the carbonized and activated samples exhibit broader, overlapping bands due to the strong absorption of carbon. In the case of these samples, the IR spectra exhibit a peak that is characteristic of $\mathrm{C}=\mathrm{C}$ asymmetric stretching vibrations in aromatic rings at $\sim 1590$ $\mathrm{cm}^{-1}$ for the carbonized sample and in the $1630-1660 \mathrm{~cm}^{-1}$ range for the activated samples. This peak seems to have a shoulder at around $1710 \mathrm{~cm}^{-1}$, which may be assigned to $\mathrm{C}=\mathrm{O}$ stretching vibrations [23]. These carbons also exhibit a band at around $1290-1320 \mathrm{~cm}^{-1}$ that can be attributed to a C-O-C asymmetric stretching vibration. Moreover, bands indicating the presence of sulphur species are present at $920 \mathrm{~cm}^{-1}$ and 
$780 \mathrm{~cm}^{-1}$, which may be assigned to C-S stretching vibrations [23]. Further information about the nature of the sulphur and oxygen functional groups is achieved by X-ray photoelectron spectroscopy (XPS). The C 1s and S 2p core level spectra of the polythiophene, carbonized polythiophene and porous carbons are shown in Figure 4. In the case of the polymer (PTh), two regions are identified below the envelope of the $\mathrm{C} 1 \mathrm{~s}$ spectrum: a) a main peak at around $284.8 \mathrm{eV}$ attributable to carbon atoms bonded directly to other carbons (thiophene ring) and b) a broad shoulder at higher binding energies, which can be deconvoluted into two peaks at $286.6 \mathrm{eV}$ and $288.8 \mathrm{eV}$. The peak at $286.6 \mathrm{eV}$ may be assigned to carbon atoms bonded to oxygen (ether, $\mathrm{C}-\mathrm{O}$ ) or sulphur (C-S), whereas the peak at $288.8 \mathrm{eV}$ can be attributed to carbons bonded to both ether and carbonyl oxygen atoms [26, 27]. The incorporation of carbonyl or ether functional groups to polythiophene is a result of the hydrolysis reaction that the $\mathrm{CH}_{3} \mathrm{CN}$ (solvent) undergoes in the polymerization medium as Jeon et al have recently reported [26]. In the S 2p XPS spectra of polythiophene, a doublet appears at 163.9 and 165.2 $\mathrm{eV}$, which is assigned to thiophene-like sulphur [28, 29]. The C 1s XPS spectrum of the carbonized polythiophene (C-PTh) is composed of four peaks. The two lower energy binding peaks correspond to carbon atoms with $\mathrm{sp}^{2}$ hybridization $(284.6 \mathrm{eV})$ and $\mathrm{sp}^{3}$ hybridization $(285.7 \mathrm{eV})$, whereas the other two higher energy binding peaks, at 286.6 and $289.2 \mathrm{eV}$, are assigned as for polythiophene (vide supra). The $\mathrm{S} 2 \mathrm{p}$ spectrum of $\mathrm{C}$ PTh is composed of two doublets, a lower energy doublet (164.0 and $165.3 \mathrm{eV}$ ) which can be assigned to -C-S-C- sulphide bridges, and a high energy doublet (167.2 and $168.5 \mathrm{eV})$ which is consistent with $-\mathrm{C}-\mathrm{S}(\mathrm{O})_{2}-\mathrm{C}$ - sulphone bridges $[16,30,31]$. The sulphone bridges represent only $5.2 \%$ of the total sulphur content, which indicates that most of the sulphur present in the C-PTh sample (13.8 wt \%) forms sulphide bridges. In the case of the activated carbons, the deconvolution of the $\mathrm{C} 1 \mathrm{~s}$ spectra show that they 
are composed of several peaks at 284.4-284.5 eV, 284.9-285.0 eV, 287.1-287.2 eV, 289.1-289.3 $\mathrm{eV}$ and 291.2-291.5 eV. The main signal at $\sim 284.5 \mathrm{eV}$ corresponds to $\mathrm{C}=\mathrm{C}$, whereas the signal at $284.9-285.0 \mathrm{eV}$ is assigned to $\mathrm{C}-\mathrm{H}_{\mathrm{x}}$. The signals at 287.1287.2 and 289.1-289.3 eV can be attributed to carbon bonded to oxygen in ether or hydroxyl groups ( $\mathrm{C}-\mathrm{O}$ and $\mathrm{C}-\mathrm{OH}$, respectively) or to sulphur $(\mathrm{C}-\mathrm{S})$, and to the carbon bonded to oxygen atoms in carbonyl $(\mathrm{C}=\mathrm{O})$ respectively. Finally, the signal at 291.2$291.5 \mathrm{eV}$ corresponds to the $\pi-\pi^{*}$ shake-up peak [32]. On the other hand, the $\mathrm{S} 2 \mathrm{p}$ signal of the activated carbons is composed of two doublets; a lower energy doublet, S $2 \mathrm{p}_{3 / 2}$, at 163.8-164.2 and 165.1-165.5 eV which can be assigned to sulphide bridges, and a high energy doublet, $\mathrm{S} 2 \mathrm{p}_{5 / 2}$, at 168.6-169.1 and 169.9-170.4 eV which is consistent with sulphone bridges [31, 33]. Several examples of S-doped carbons produced by simple carbonization of sulphur-rich precursors (i. e. polythiophene, cysteine, etc) can be found in the literature $[13,16,17]$. The sulphur present in these carbons is almost exclusively forming sulphide bridges (-C-S-C-) due to the fact that reducing conditions prevail during the carbonization step. On the contrary, the chemical activation of polythyophene occurs under oxidizing conditions, which induce the formation not only of numerous oxygen functional groups but also of a large number of sulphone functional groups besides of sulphide bridges. Indeed, a large fraction of the sulphur present in the activated carbons forms sulphone bridges and this percentage increases as the activation temperature diminishes (i. e. $57 \%$ for CT-2-600, $36 \%$ for CT-2-700 and $30 \%$ for CT-2-850). These results lead us to conclude that: a) the sulphur present in the carbonized polythiophene almost exclusively forms sulphide groups, b) the activated carbons contain a large number of sulphide and sulphone bridges and c) the (sulphone/sulphide) ratio of the activated carbons diminishes as the activation temperature increases. 


\section{Conclusions}

We have demonstrated an easy one-step synthesis strategy for the fabrication of sulphur-doped porous carbons with high apparent surface areas (up to $3000 \mathrm{~m}^{2} \mathrm{~g}^{-1}$ ) and large pore volumes (up to $1.75 \mathrm{~cm}^{3} \mathrm{~g}^{-1}$ ), which predominantly correspond to micropores. The choice of polythiophene as carbon precursor is the key to obtaining, via a simple one-step chemical activation procedure with $\mathrm{KOH}$, porous carbons that contain large amounts of sulphur and display outstanding textural and chemical properties. Interestingly, porous carbons prepared under mild activation conditions $(\mathrm{KOH} / \mathrm{PTh}=2)$ exhibit a superior pore development to those prepared with $\mathrm{KOH} / \mathrm{PTh}=4$. The textural properties of these activated carbons can be tailored by modifying the activating conditions (i. e. the amount of activating agent and temperature). Thus, an increase in the reaction temperature causes a gradual enlargement of the pores. These polythiophene-based porous carbons have large sulphur contents in the 3-12 wt \% range, which decrease as the reaction temperature rises. The sulphur present in these carbons is composed exclusively of two types of functional groups (i. e. sulphide -C-S$\mathrm{C}$ - and sulphone $-\mathrm{C}-\mathrm{SO}_{2}-\mathrm{C}$-), which act as bridges between adjacent aromatic rings. It was observed that the fraction of sulphone bridges gradually diminishes as the reaction temperature rises. Finally, we want to point out that the properties of these carbons (i. e. a large pore development combined with a high sulphur content) immediately suggests that they would make exceptional sorbents for mercury capture in liquid phase.

Acknowledgments. The financial support for this research work provided by the Spanish MCyT (MAT2008-00407) is gratefully acknowledged. M. S. thanks the Spanish MCyT for the award of a Postdoctoral Mobility contract. 


\section{References}

[1] D. S. Su, R. Schlögl, ChemSusChem 3 (2010)136-68.

[2] A. Vinu, M. Miyahara, K. Ariga, J. Phys. Chem. B 109 (2005) 6436-41.

[3] S. Choi, J. H. Drese, C. W. Jones, ChemSusChem 2 (2009) 796-854.

[4] Y. Yürüm, A. Taralpa, T. N. Veziroglu, Int. J. Hydrogen Energ. 34 (2009) 3784-98.

[5] Z. Wu, D. Y. Zhao, Chem. Commun. 47 (2011) 3332-8.

[6] K-Y. Chan, J. Ding, J. Ren, S. Cheng, K. Y. Tsang, J. Mater. Chem. 14 (2004) 50516.

[7] J. Lee, S. Han, T. Hyeon, J. Mater. Chem. 14 (2004) 478-86.

[8] M. Sevilla, A. B. Fuertes, Energy Environ. Sci. 4 (2011) 1765-71.

[9] M. Sevilla, A. B. Fuertes, R. Mokaya, Energy Environ. Sci. 4 (2011) 1400-10.

[10] L. Wei, M. Sevilla, A. B. Fuertes, R. Mokaya, G. Yushin, Adv. Energy Mater. 1 (2011) 356-61.

[11] A. Stein, Z. Wang, M. A. Fierke, Adv. Mater. 21 (2009) 265-93.

[12] Y. F. Jia, B. Xiao, K. M. Thomas, Langmuir 18 (2002) 470-8.

[13] Y. Shin, G. E. Fryxell, W. Um, K. Parker, S. V. Mattigod, R. Skaggs, Adv. Funct. Mater. 17 (2007) 2897-2901.

[14] G. Hasegawa, M. Aoki, K. Kanamori, K. Nakanishi, T. Hanada, K. Tadanaga, J. Mater. Chem. 21 (2011) 2060-3.

[15] I. H. Lee, S. H. Joo, J. H. Kim, D. J. You, J. M. Kim, J-N. Park et al., J. Mater. Chem. 19 (2009) 5934-9.

[16] C. H. Choi, S. H. Park, S. I. Woo, Green Chem. 13 (2011) 406-12.

[17] G. Hasegawa, K. Kanamori, K. Nakanishi, T. Hanada, Carbon 48 (2010) 1757-66.

[18] M. Sevilla, P. Valle-Vigón, A. B. Fuertes, Adv. Func. Mater. 21 (2011) 2781-7.

[19] M. Sevilla, R. Mokaya, A. B. Fuertes, Energy Environ. Sci. 4 (2011) 2930-6.

[20] M. A. Lillo-Rodenas, J. Juan-Juan, D. Cazorla-Amoros, A. Linares-Solano, Carbon 42 (2004) 1371-5. 
[21] X-G. Li, J. Li, M. R. Huang, Chem. Eur. J. 15 (2009) 6446-55.

[22] M. R. Karim, C. J. Lee, M. S. Lee, J. Polym. Sci. Part A: Polym. Chem. 44 (2006) 5283-90.

[23] G. Socrates, Infrared and Raman Characteristic Group Frequencies. 3 ed. Wiley, New York 2005.

[24] M. R. A. Alves, H. D. R. Calado, C. L. Donnici, T. Matencio, Synth. Met. 160 (2010) 22-7.

[25] A. Gök, M. Omastova, A. G. Yavuz, Synth. Met. 157 (2007) 23-9.

[26] S. S. Jeon, S. J. Yang, K-J. Lee, S. S. Im, Polymer 51 (2010) 4069-76.

[27] H. Y. Seung, J. E. Whitten, Synth. Met. 114 (2000) 305-12.

[28] M-D. Lu, S-M. Yang, Synth. Met. 154 (2005) 73-6.

[29] W. S. Baker, J. W. Long, R. M. Stroud, D. R. Rolison, J. Non-Cryst. Sol. 350 (2004) 80-7.

[30] M. Matsuda, K. Funabashi, J. Polym. Sci. Part A: Polym. Chem. 25 (1987) 669-73.

[31] D. J. Malik, A. W. Trochimczuk, A. Jyo, W. Tylus, Carbon 46 (2008) 310-9.

[32] H. Darmstadt, C. Roy, S. Kaliaguine, S. J. Choi, R. Ryoo, Carbon 40 (2002) 267383.

[33] Y. P. Wua, S. Fanga, Y. Jianga, R. Holze, J. Pow. Sources 108 (2002) 245-9. 
Table 1. Textural properties and chemical composition of polythiophene-based carbons.

\begin{tabular}{|c|c|c|c|c|c|c|c|c|c|}
\hline \multirow{2}{*}{ Sample } & \multicolumn{4}{|c|}{ Textural properties } & \multicolumn{4}{|c|}{ Chemical composition [wt \%] } & \multirow{2}{*}{$\begin{array}{c}\text { Yield } \\
{[\mathrm{wt} \%][\mathrm{c}]}\end{array}$} \\
\hline & $\mathrm{S}_{\mathrm{BET}}\left[\mathrm{m}^{2} \mathrm{~g}^{-1}\right]$ & $\mathrm{S}_{\text {micro }}\left[\mathrm{m}^{2} \mathrm{~g}^{-1}\right][\mathrm{a}]$ & $\mathrm{V}_{\mathrm{p}}\left[\mathrm{cm}^{3} \mathrm{~g}^{-1}\right][\mathrm{b}]$ & $\mathrm{V}_{\text {micro }}\left[\mathrm{cm}^{3} \mathrm{~g}^{-1}\right][\mathrm{a}]$ & $\mathrm{S}$ & $\mathrm{C}$ & $\mathrm{O}$ & $\mathrm{H}$ & \\
\hline PTh & - & - & - & - & 28.2 & 57.7 & 11.1 & 2.96 & - \\
\hline C-PTh & 550 & 480 & 0.43 & 0.22 & 13.8 & 77.1 & 8.8 & 0.28 & 56 \\
\hline CT-2-600 & 1790 & 1730 & $0.89(89)$ & 0.79 & 8.5 & 72.3 & 18.0 & 1.24 & 42 \\
\hline CT-2-700 & 2630 & 2460 & $1.28(86)$ & 1.10 & 4.5 & 81.4 & 13.3 & 0.83 & 34 \\
\hline CT-2-750 & 2810 & 2560 & $1.42(80)$ & 1.15 & 2.8 & 87.1 & 9.9 & 0.17 & 28 \\
\hline CT-2-800 & 3010 & 2610 & $1.57(75)$ & 1.19 & 3.4 & 88.3 & 8.2 & 0.13 & 25 \\
\hline CT-2-850 & 3000 & 2300 & $1.75(63)$ & 1.11 & 2.5 & 89.0 & 8.2 & 0.25 & 22 \\
\hline CT-4-600 & 1430 & 1380 & $0.69(91)$ & 0.63 & 11.8 & 67.8 & 19.7 & 0.70 & 40 \\
\hline CT-4-700 & 1890 & 1830 & $0.90(90)$ & 0.83 & 4.4 & 83.0 & 12.3 & 0.33 & 30 \\
\hline CT-4-800 & 2670 & 2440 & $1.32(84)$ & 1.11 & 5.8 & 87.7 & 6.4 & 0.12 & 26 \\
\hline CT-4-850 & 2470 & 2080 & $1.32(74)$ & 0.98 & 3.5 & 79.8 & 16.4 & 0.27 & 21 \\
\hline
\end{tabular}

[a] Micropore surface area and micropore volume were determined by the t-plot method; [b] Total pore volume at $\mathrm{p} / \mathrm{p}_{\mathrm{o}} \sim 0.99$. The values in parenthesis are the percentage of micropore volume occupied by the micropores $(<2 \mathrm{~nm})$ in relation to the total pore volume; [c] Percentage of carbonaceous product obtained after the carbonization or activation of polythiophene. 

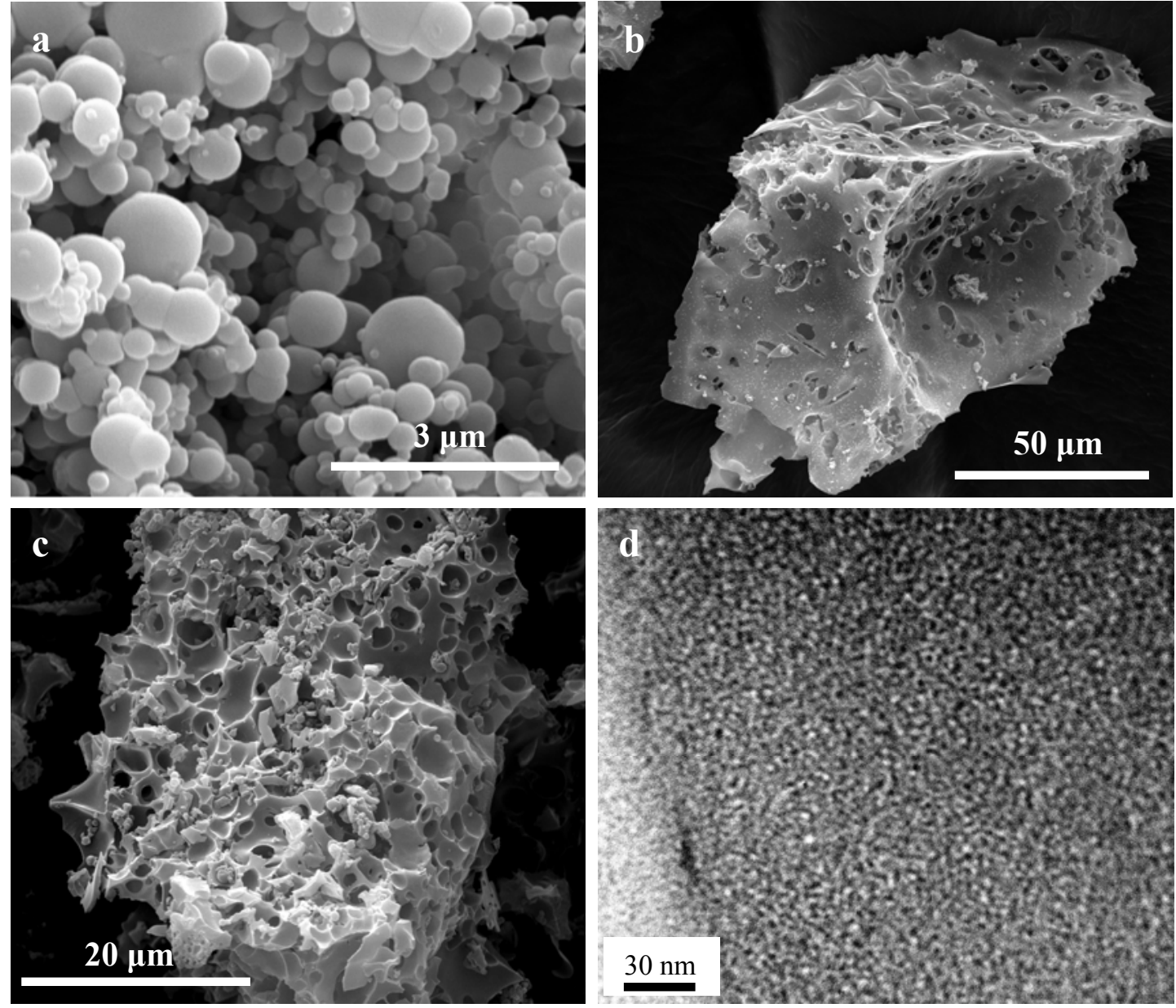

Figure 1. SEM images of polythiophene (a) and activated carbons: CT-2-600 (b), CT-2800 (c). TEM image of CT-2-600 (d). 

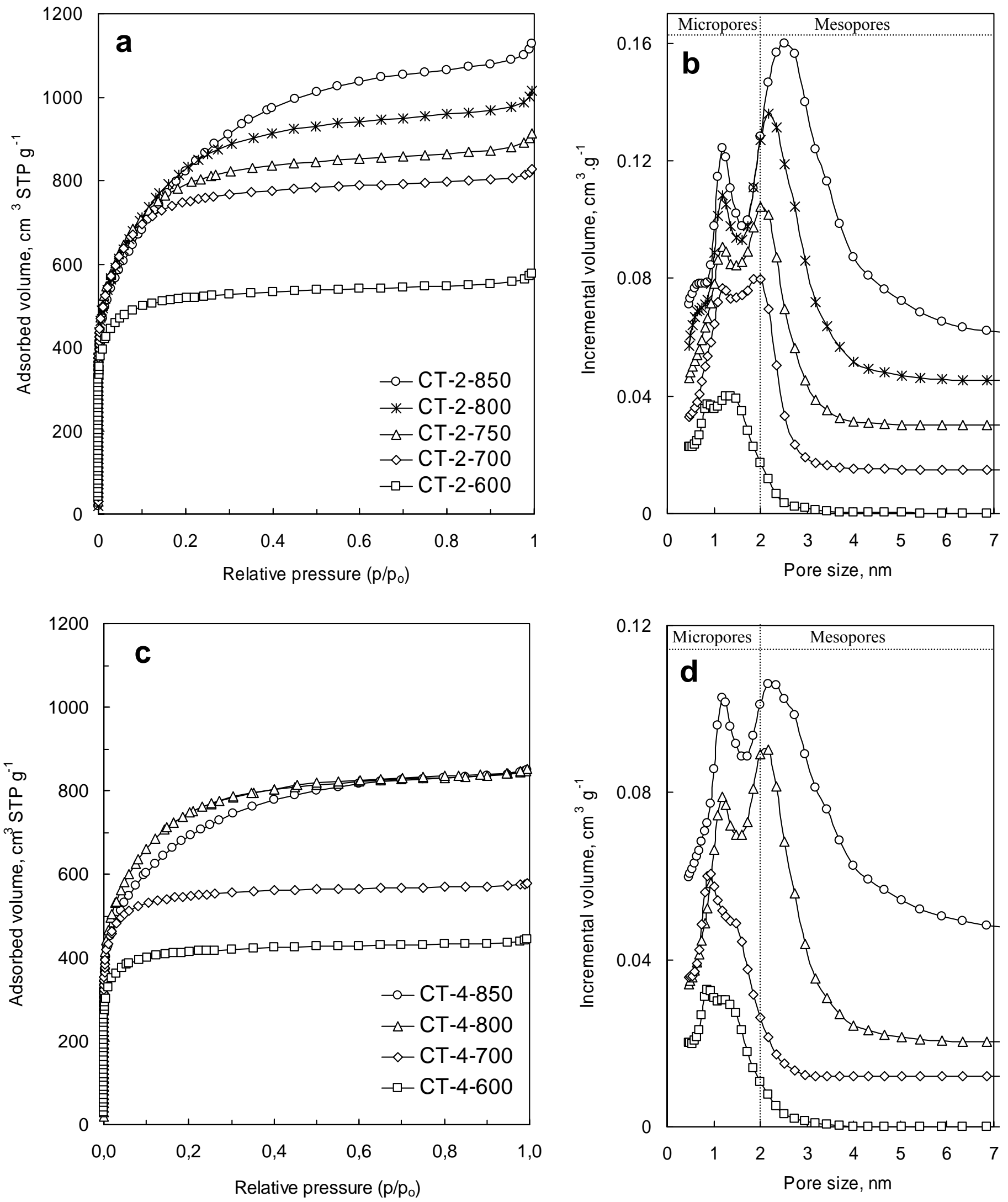

Figure 2. $\mathrm{N}_{2}$ sorption isotherms $(\mathrm{a}, \mathrm{c})$ and pore size distributions $(\mathrm{b}, \mathrm{d})$ of activated carbons prepared with $\mathrm{KOH} / \mathrm{PTh}=2(\mathrm{a}, \mathrm{b})$ and $\mathrm{KOH} / \mathrm{PTh}=4(\mathrm{c}, \mathrm{d})$ at different activation temperatures. For the shake of clarity, the PSDs in Figures $b$ and $d$ have been upshifted. 


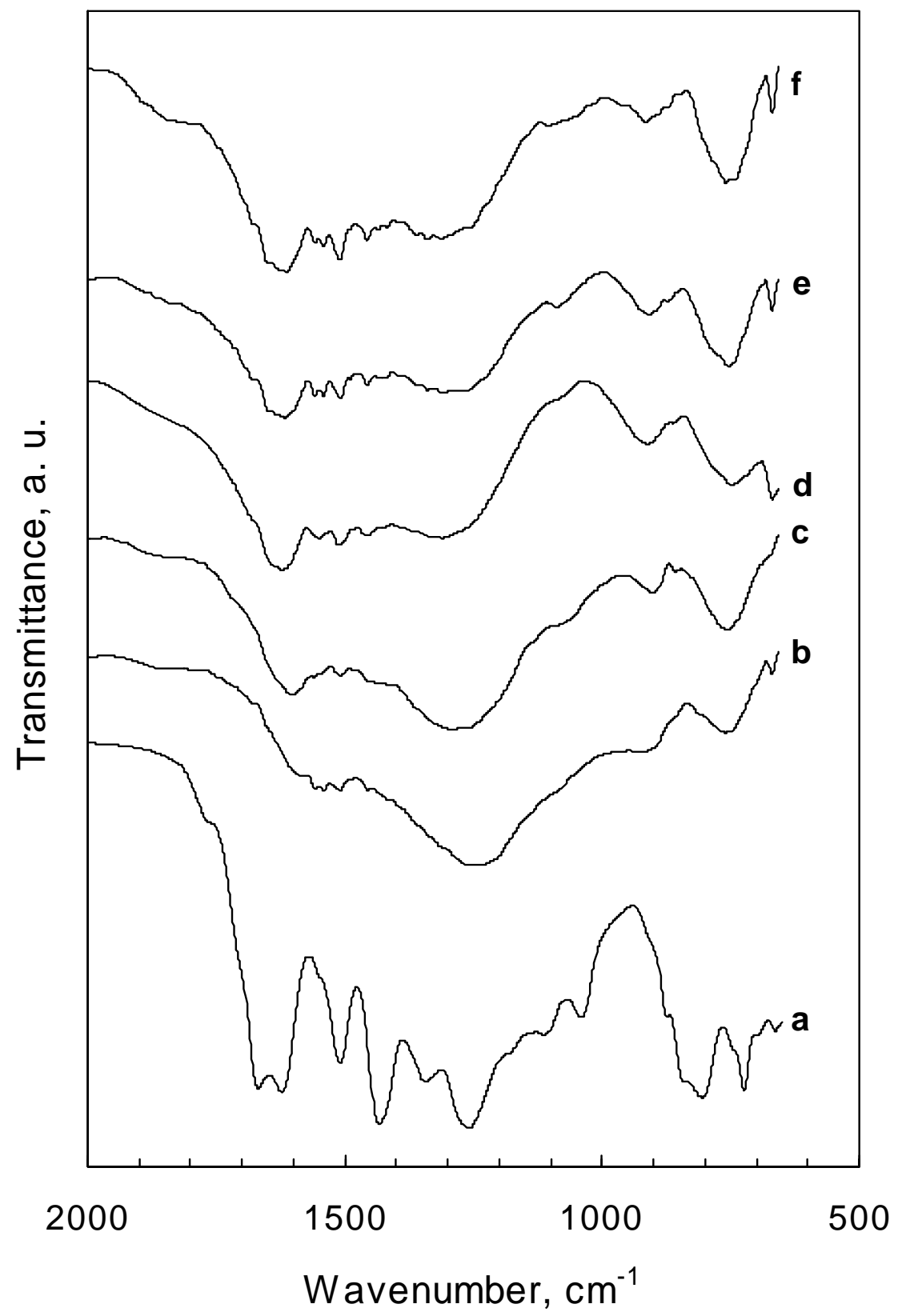

Figure 3. Infrared spectra of: (a) PTh, (b) C-PTh, (c) CT-2-600, (d) CT-2-700, (e) CT2-800 and (f) CT-2-850. 


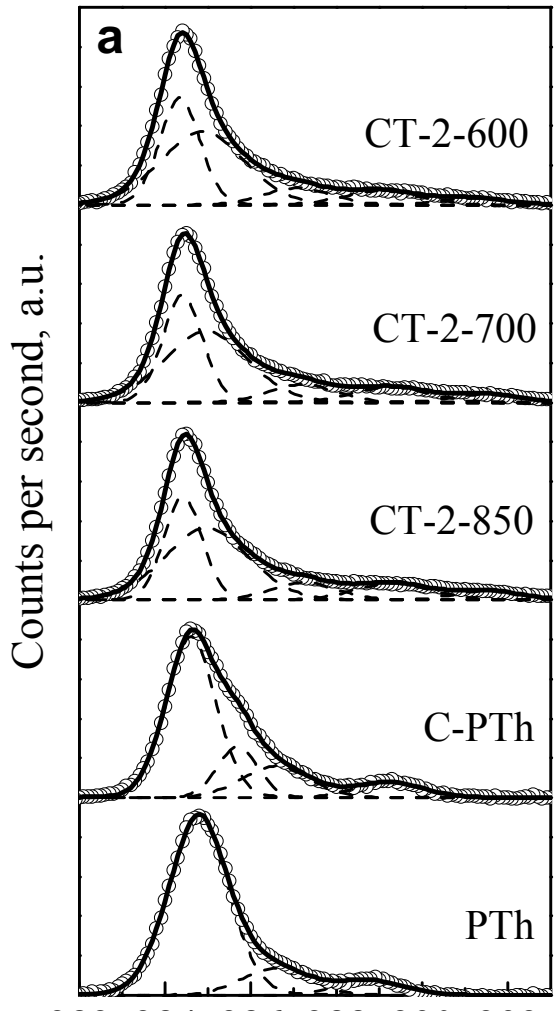

282284286288290292

Binding Energy, eV

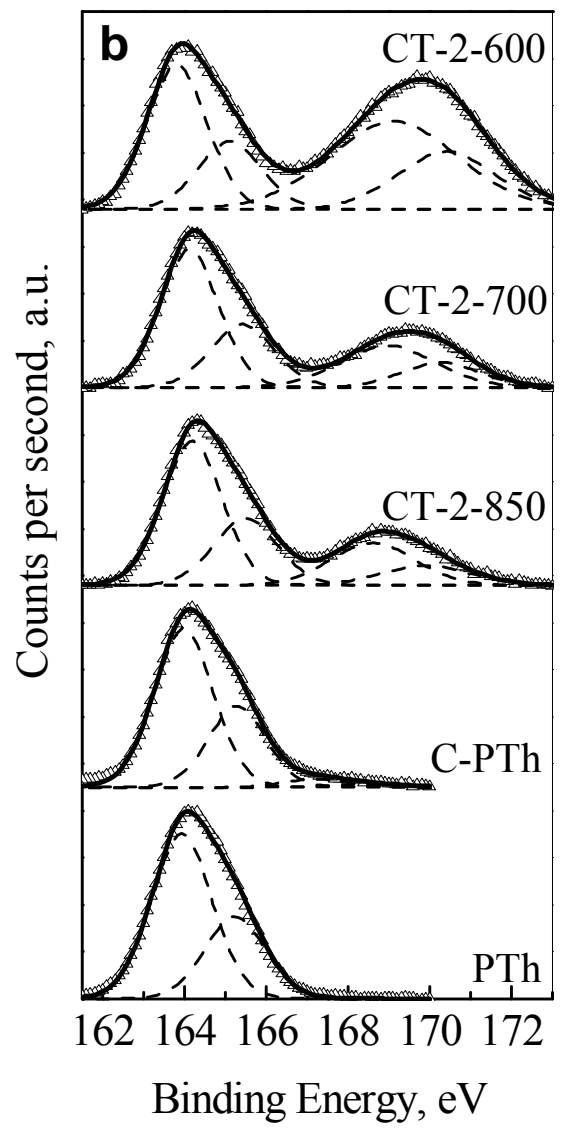

Figure 4. (a) C $1 \mathrm{~s}$ and (b) S $2 p$ core-level XPS spectra of polythiophene and polythiophene-based carbons. 